\title{
Socioeconomic inequalities in cause specific mortality among older people in France
}

\author{
Gwenn Menvielle*1,2, Annette Leclerc ${ }^{1,2}$, Jean-François Chastang 1,2 and Danièle Luce 1,2
}

\begin{abstract}
Background: European comparative studies documented a clear North-South divide in socioeconomic inequalities with cancer being the most important contributor to inequalities in total mortality among middle aged men in Latin Europe (France, Spain, Portugal, Italy). The aim of this paper is to investigate educational inequalities in mortality by gender, age and causes of death in France, with a special emphasis on people aged 75 years and more.

Methods: We used data from a longitudinal population sample that includes $1 \%$ of the French population. Risk of death (total and cause specific) in the period 1990-1999 according to education was analysed using Cox regression models by age group (45-59, 60-74, and 75+). Inequalities were quantified using both relative (ratio) and absolute (difference) measures.

Results: Relative inequalities decreased with age but were still observed in the oldest age group. Absolute inequalities increased with age. This increase was particularly pronounced for cardiovascular diseases. The contribution of different causes of death to absolute inequalities in total mortality differed between age groups. In particular, the contribution of cancer deaths decreased substantially between the age groups 60-74 years and 75 years and more, both in men and in women.

Conclusions: This study suggests that the large contribution of cancer deaths to the excess mortality among low educated people that was observed among middle aged men in Latin Europe is not observed among French people aged 75 years and more. This should be confirmed among other Latin Europe countries.
\end{abstract}

\section{Background}

Socioeconomic inequalities in total and cause specific mortality have been consistently reported throughout Europe [1,2]. Within this general pattern, large differences are observed between countries both in the magnitude of these inequalities and in the weight of different causes of death in inequalities in total mortality. In particular, a specific situation is found regarding cancer mortality. Among men, studies have shown larger inequalities in cancer mortality in France, Belgium and Switzerland. Moreover, the main contributor to inequalities in total mortality was cancer in Latin Europe countries (France, Spain, Portugal and Italy), and cardiovascular diseases in Northern Europe, especially in Nordic countries $[1,3]$. The picture was less contrasted among women. Moderate

\footnotetext{
* Correspondence: Gwenn.Menvielle@inserm.fr

1 Inserm U1018, Epidemiology of occupational and social determinants of health, Center for Research in Epidemiology and Population Health, Inserm, Villejuif, France

Full list of author information is available at the end of the article
}

inequalities in cancer mortality were found in most European countries except in Spain or Slovenia where no inequalities or even reverse inequalities with higher mortality rates among women with lower socioeconomic position were observed [4]. Also, in women, cardiovascular diseases contributed most to inequalities in total mortality in all countries [1].

Most available studies were conducted among middle aged people and little is known about older people. Fewer studies investigated socioeconomic inequalities in total mortality [5-8] or by cause of death [7,9] among people aged 70 or older. Because mortality rates increase with age, it is expected that relative inequalities will decrease. On the contrary, absolute inequalities that may be quantified using mortality rates difference between educational groups will increase $[10,11]$. Within this general pattern, there may be variations by cause of death. Studies consistently reported lower but still statistically significant relative inequalities in mortality for total mortality and most causes of death among elderly people when compared 
with younger people [5-9]. Differences were reported between age groups in the weight of the different causes of death in socioeconomic inequalities in total mortality [7]. Particularly, the contribution of cancer to these inequalities decreased with increasing age. This was found in a pooled European study and thus it still remains unknown whether this decrease was consistently observed in all countries, in particular if it is also observed in countries like France where cancer mortality largely contributes to socioeconomic inequalities in total mortality among middle aged men.

We propose to give some insight to this question by using a French dataset representative of the population. The aim of this paper is to specifically investigate socioeconomic inequalities in mortality by age and causes of death in France, with a special emphasis on men and women aged over 75 and on cancer mortality.

\section{Methods}

We used data from a longitudinal population sample that includes $1 \%$ of the French population [12]. We excluded individuals born outside metropolitan France because their vital status was incompletely recorded. Analyses were conducted among three age groups: $45-59$ years, 6074 years, and 75 years and over. For the age group 45-59 years, each subject's follow-up started at 01/01/1990 or his/her $45^{\text {th }}$ birthday, whichever occurred last, and ended at his/her date of death, his/her $60^{\text {th }}$ birthday or $31 / 12 /$ 1999, whichever occurred first. The same applied for the two other age groups. The analysis was conducted among 73374 and 77155 men and women aged 45-59 years in 1990, 51921 and 61895 men and women aged 60-74 years, and 24509 and 41601 men and women aged 75 years and more.

The causes of death were obtained by linkage with the French national death registry (Inserm, CepiDc). The causes of death were identified for $98 \%$ of the deceased. We investigated total mortality but also specific causes of death: total cancers (ICD9:140-239), lung cancer (ICD9:162), colorectal cancer (ICD9:153-154), upper aerodigestive tract cancers (UADT) (ICD9:140-150,161), prostate cancer (ICD9:), breast cancer (ICD9:174), cardiovascular diseases (CVD) (ICD9:390-459), ischemic heart disease (IHD) (ICD9: 410-414), cerebrovascular disease (ICD9: 430-438), non cancer-non CVD (ICD9 codes not in 140-239 or 390-459) [13].

The socioeconomic position was measured using education declared at 1990 census and was categorized into four groups: no education, primary education, vocational secondary education, general secondary education and higher.

When quantifying inequalities in different age groups, several methodological aspects should be considered. First, the level of mortality strongly differs between age groups. Therefore, inequalities are best quantified using both relative and absolute measures. A relative measure of inequalities quantifies a ratio whereas an absolute measure quantifies a difference and thus takes into account the absolute level of mortality. An absolute measure of inequalities can be interpreted as an excess mortality among people with low education when compared with people with high education and thus quantifies the burden of the disease in the population. Second, the educational distribution substantially differed by gender and age group. This may have an impact when comparing socioeconomic inequalities between the different groups. Therefore, we quantified inequalities using indices that take into account the size and relative position of each education level and thus minimize problems due to noncomparability in educational distribution between groups compared. We computed relative indices of inequality (RIIs) to quantify relative inequalities and slope indices of inequality (SIIs) to quantify absolute inequality $[14,15]$.

The computation of these indices is based on a relative measure of education. This is a ranked variable that equals, for each educational group, the mean proportion of the population with a higher level of education. Let us consider a population with the following educational distribution: $20 \%$ with high education, $30 \%$ with middle education, and $50 \%$ with low education. For people with high education, this ranked variable is assigned a value of 0.20 / $2=0.10$. For people with middle education, it is assigned a value of $0.20+0.30 / 2=0.35$. For people with low education, it is assigned a value of $0.20+0.30+0.50 / 2=0.75$. The ranked variable was computed separately for each stratum of sex and age category.

The RII was computed using a Cox regression model with this ranked variable as explanatory variable and mortality as the outcome variable. Age was used as time variable. The RII corresponds to the estimate obtained for education (the ranked variable). The SII was then derived from the RII using the following formula: SII = $2 * \mathrm{MR} *(\mathrm{RII}-1) /(\mathrm{RII}+1)$ with MR the mortality rate [1]. Thus, the RII and the SII express inequality within the whole socioeconomic continuum. Both indices use all the available data and are not restricted to comparisons of extreme groups by treating education as a continuous variable. The confidence intervals for both indices were computed with Bootstrap [16].

We also computed age-standardised mortality rates by sex and age group, and by sex, age group and education level, using the 1995 European population as standard. Cause of death certification may be less accurate among the oldest people. Therefore, we conducted additional analyses restricted to the age group 75-84 and thus excluded the very old people whose cause of death may be the least accurately reported. By doing so, we could investigate whether the conclusions drawn for the age 
group 75 years and more still hold in this restricted group. In addition, we calculated the share of specific causes of death in absolute inequalities in total mortality by dividing the SII observed for a specific cause of death by that found for total mortality.

\section{Results}

Education level differs by age group and gender (Table 1). The percentage of subjects with an upper secondary or higher education increased from $6 \%$ and 14\% among women and men aged 75 years and more to $22 \%$ and $26 \%$ among women and men aged 45-59 years. Cause specific mortality rates differed between age-groups. Among people aged 45-59 and 60-74 years, cancer deaths accounted for about half of total mortality both in men and women (Table 2). Among people aged 75 years and more, CVD were the most prevalent causes of death and accounted for $36 \%$ and $42 \%$ of total mortality in men and women. A reverse educational gradient was observed for total mortality and CVD mortality for all age groups both in men and women (Figure 1). For total cancer mortality, this gradient was less pronounced among women and it was not observed in the oldest age group for men or for women.

The relative inequalities in total mortality as quantified with RII decreased as age increased (Table 2). The RII remained statistically significant among the oldest age group $($ RIImen $=1.55,95 \%$ CI: 1.41-1.70; RIIwomen $=$ 1.46, 1.34-1.58). Inequalities decreased with increasing age for most causes of deaths. Among men aged 75 and over, the RII was close to 1 for lung cancer and the estimates were not statistically significant for lung, colorectal, and prostate cancer, and IHD. For prostate cancer, the RII increased in the oldest age group. Among women aged 75 and over, the RII remained statistically significant for cardiovascular mortality $(\mathrm{RII}=1.51,1.33-1.71)$ and non cancer-non CVD causes of death (RII $=1.60,1.41$ 1.81 ) but not any more for cancer mortality (RII $=1.07$, 0.87-1.30). For breast cancer, the RII were higher than 1 and similar in all age groups but the pattern by educational level differed between age groups (results not shown). Higher mortality rates were found among less educated women aged 45-59 years and 60-74 years. Among women aged 75 years and more, a U-shape relationship was observed with lower mortality among women with primary or vocational secondary education.

The absolute inequalities as measured with SII increased as age increased (Table 3). This increase was particularly pronounced for CVD. Among men, the SII increased from 138 (per 100000 person years) in the age group 45-59 years to 439 in the age group 60-74 years and to 1340 in the age group 75 years and more. Among women, the figures were respectively 42,257 and 1168 . A large increase was also observed for non cancer-non CVD deaths both in men (from 281 to 698 to 2330) and women (from 115 to 335 to 1353).

No increase in SII was observed for total cancer mortality between the two oldest age groups: the SII remained stable among men from 572 to 629 and decreased among women from 145 to 69 , the latter not being significantly different from 0 . When investigating the situation by cancer site, the SII decreased among men for lung cancer mortality and did not reach statistical significance in the oldest age group. The SII remained stable and high for UADT cancers. For colorectal and prostate cancer, the SII increased but did not reach statistical significance. In women, the SII remained small and not significant in all age groups for all cancer specific causes of death.

Table 1: Education level by gender and age group

\begin{tabular}{|c|c|c|c|c|c|c|}
\hline \multirow[b]{2}{*}{$\begin{array}{l}\text { Education } \\
\text { level (\%) }\end{array}$} & \multicolumn{3}{|c|}{ Men } & \multicolumn{3}{|c|}{ Women } \\
\hline & 45-59 & $60-74$ & $75+$ & 45-59 & $60-74$ & $75+$ \\
\hline No education & 20 & 29 & 38 & 22 & 34 & 47 \\
\hline $\begin{array}{l}\text { Primary } \\
\text { education }\end{array}$ & 20 & 33 & 37 & 28 & 37 & 36 \\
\hline $\begin{array}{l}\text { Vocational } \\
\text { secondary } \\
\text { education }\end{array}$ & 34 & 21 & 11 & 28 & 18 & 11 \\
\hline $\begin{array}{l}\text { Upper } \\
\text { secondary } \\
\text { education or } \\
\text { higher }\end{array}$ & 26 & 17 & 14 & 22 & 11 & 6 \\
\hline
\end{tabular}


Table 2: Relative index of inequality (RII) and 95\% confidence intervals (CI) for education, by age group, gender and cause of death

\begin{tabular}{|c|c|c|c|c|c|c|c|c|c|}
\hline \multirow[b]{2}{*}{ Cause of death } & \multicolumn{3}{|c|}{ 45-59 } & \multicolumn{3}{|c|}{$60-74$} & \multicolumn{3}{|c|}{$75+$} \\
\hline & $\mathbf{N}$ & RII & $95 \% \mathrm{Cl}$ & $\mathbf{N}$ & RII & $95 \% \mathrm{Cl}$ & $\mathbf{N}$ & RII & $95 \% \mathrm{Cl}$ \\
\hline \multicolumn{10}{|l|}{ Men } \\
\hline All deaths & 2808 & 3.00 & $2.50-3.58$ & 7176 & 2.15 & $1.92-2.40$ & 10689 & 1.55 & $1.41-1.70$ \\
\hline All cancers & 1291 & 2.52 & $1.91-3.26$ & 3165 & 1.76 & $1.49-2.08$ & 2630 & 1.31 & $1.08-1.57$ \\
\hline Lung cancer & 362 & 2.39 & $1.41-3.89$ & 833 & 1.68 & $1.21-2.32$ & 403 & 1.05 & $0.66-1.67$ \\
\hline UADT cancers & 396 & 4.93 & $3.06-7.74$ & 506 & 3.59 & $2.40-5.65$ & 189 & 2.95 & $1.43-6.63$ \\
\hline $\begin{array}{l}\text { Colorectal } \\
\text { cancer }\end{array}$ & 68 & 1.11 & $0.33-3.38$ & 261 & 1.62 & $0.90-3.00$ & 317 & 1.51 & $0.89-2.67$ \\
\hline Prostate cancer & 17 & 1.02 & $0.04-40.4$ & 195 & 1.02 & $0.54-1.91$ & 536 & 1.36 & $0.90-2.14$ \\
\hline CVD & 474 & 3.77 & $2.40-5.93$ & 1916 & 2.06 & $1.67-2.60$ & 3889 & 1.46 & $1.24-1.69$ \\
\hline IHD & 192 & 2.68 & $1.40-5.56$ & 767 & 1.40 & $1.00-1.96$ & 1087 & 1.20 & $0.89-1.62$ \\
\hline $\begin{array}{l}\text { Cerebrovascular } \\
\text { diseases }\end{array}$ & 101 & 2.23 & $0.95-5.76$ & 394 & 2.78 & $1.79-4.96$ & 989 & 1.37 & $1.01-1.88$ \\
\hline $\begin{array}{l}\text { Non cancer-non } \\
\text { CVD }\end{array}$ & 1043 & 3.37 & $2.51-4.63$ & 2095 & 3.07 & $2.41-3.78$ & 4170 & 1.85 & $1.58-2.13$ \\
\hline \multicolumn{10}{|l|}{ Women } \\
\hline All deaths & 1197 & 2.38 & $1.78-3.19$ & 3708 & 2.30 & $1.96-2.72$ & 15706 & 1.46 & $1.34-1.58$ \\
\hline All cancers & 615 & 1.57 & $1.07-2.40$ & 1562 & 1.44 & $1.12-1.84$ & 2457 & 1.07 & $0.87-1.30$ \\
\hline Lung cancer & 51 & 0.69 & $0.15-2.72$ & 109 & 0.81 & $0.30-2.15$ & 126 & 0.87 & $0.38-2.11$ \\
\hline UADT cancers & 38 & 5.35 & $0.96-40.1$ & 39 & 4.39 & $0.92-28.3$ & 66 & 0.97 & $0.26-3.80$ \\
\hline $\begin{array}{l}\text { Colorectal } \\
\text { cancer }\end{array}$ & 55 & 5.35 & $1.22-48.1$ & 191 & 1.25 & $0.59-2.79$ & 404 & 0.84 & $0.52-1.38$ \\
\hline Breast cancer & 193 & 1.21 & $0.60-2.44$ & 333 & 1.22 & $0.73-2.09$ & 347 & 1.26 & $0.73-2.30$ \\
\hline CVD & 140 & 4.63 & $2.01-11.5$ & 918 & 3.37 & $2.43-4.73$ & 6536 & 1.51 & $1.33-1.71$ \\
\hline IHD & 27 & 3.11 & $0.50-36.3$ & 270 & 2.75 & $1.50-5.37$ & 1422 & 1.45 & $1.11-1.92$ \\
\hline $\begin{array}{l}\text { Cerebrovascular } \\
\text { diseases }\end{array}$ & 41 & 5.98 & $1.21-54.9$ & 259 & 2.89 & $1.62-5.78$ & 1824 & 1.70 & $1.33-2.17$ \\
\hline $\begin{array}{l}\text { Non cancer-non } \\
\text { CVD }\end{array}$ & 442 & 3.55 & $2.15-5.84$ & 1228 & 3.24 & $2.34-4.28$ & 6713 & 1.60 & $1.41-1.81$ \\
\hline
\end{tabular}


As a consequence of the changes in SII, the contribution of the different causes of deaths to inequalities in total mortality, as quantified by the ratio SII for specific cause of death/SII for total deaths, also substantially differed between age-groups. The contribution of cancer decreased with age from $40 \%$ (age group $45-59$ ) to $33 \%$ (age group 60-74) and to 15\% (age group 75+) among men and from $28 \%$ to $19 \%$ and to $3 \%$ among women. On the contrary, the contribution of CVD increased and reached $31 \%$ in men and $45 \%$ in women in the oldest age group.

Additional analyses conducted in the age group 75-84 supported the results observed among people aged 75 years and more. Relative inequalities were slightly higher and absolute inequalities slightly smaller than those found in the age group 75 years and more.

\section{Discussion}

\section{Summary of main findings}

We investigated educational differences in mortality by age group and especially among the oldest (age 75+). Relative inequalities were still observed in the oldest age group although the magnitude decreased when age increased. Absolute inequalities increased with age. The share of different causes of death to absolute inequalities in total mortality differed between age groups. In particular, the contribution of cancer deaths decreased substantially between the age group 60-74 years and the oldest age group. Thus, the specific "Latin Europe" pattern characterised by an important contribution of cancer deaths to the excess mortality found among low educated middle aged men was not observed among people aged 75 years and more in France.

\section{Methodological aspects}

While we used a high quality dataset made of $1 \%$ of the French population and including institutionalised persons, some limits of the data should be addressed. The choice of the socioeconomic position indicator should be discussed. Education presents several advantages, in particular it is available both among men and women and also among older people, but also drawbacks [17]. First, the meaning of education is related to age. The measures we used to quantify socioeconomic inequalities are especially well adapted to compare populations with different education distributions and thus partly account for this issue. In addition, education is determined early in adulthood and may not any more accurately describe the socioeconomic position of old people. It has been suggested that economic advantage or disadvantage accumulated over the life course as measured by long-term income or total financial assets may better capture the cumulative effects of lifetime socioeconomic position on health status in old age and may thus be more appropriate when studying older populations $[18,19]$. This information was not available in our dataset. Moreover, as we aim to study changes in inequalities with age, we had to use an indicator that was adapted to different age groups. In that sense, while not being the most adequate indicator for elderly people, education is a good indicator as it has been shown to be consistently associated with health through age groups and gender.

The mechanisms through which education may impact health are diverse [20]. In addition to consequences of education in terms of lifetime socioeconomic position, people with higher education may be more receptive to prevention messages and may have a better ability to change their health behaviour and to better use the health care system. Among elderly people, factors in relation with health care may be the most relevant. This includes more regular visits to GPs and specialists, a higher uptake of screening, a better understanding of the prevention messages or a better compliance to treatment among more educated people.

Some problems may occur with cause of death certification, especially among the oldest people. If so, the results observed in the oldest age group may be, at least partly, due to problems in cause of death certification rather than to real changes in the mechanisms of socioeconomic inequalities. Then, CVD may be more easily coded among old people certainly suffering from multiple diseases which could lead to death. To explore this hypothesis, we investigated the distribution of the associate causes of death, which are the causes of death mentioned on the death certificate in addition to the underlying and the immediate cause of death. In the oldest age group, the associate causes of death for CVD deaths were also CVD for $25 \%$ of deaths, non cancer-non CVD otherwise. The associate causes of death for cancer deaths were mainly non cancer-non CVD. This pattern did not substantially differ by education. These findings did not suggest that CVD would be more easily coded among older people. Moreover the percentage of causes of death unknown or ill-defined was small (around 3\%) and similar in all age groups stratified by sex and education. We also conducted analyses restricted to people aged 75-84. Results were consistent with those observed in the broader age group 75 years and more. The largest difference was found for non cancer-non CVD deaths, suggesting that, if any, imprecision in cause of death certification would favour a broad and heterogeneous group of diseases (non cancer-non CVD) rather than CVD. Thus, we do not believe errors in cause of death certification substantially biased our results.

External causes of death were included in the group non cancer-non CVD. When studied separately, the inequalities for external causes of death were globally 


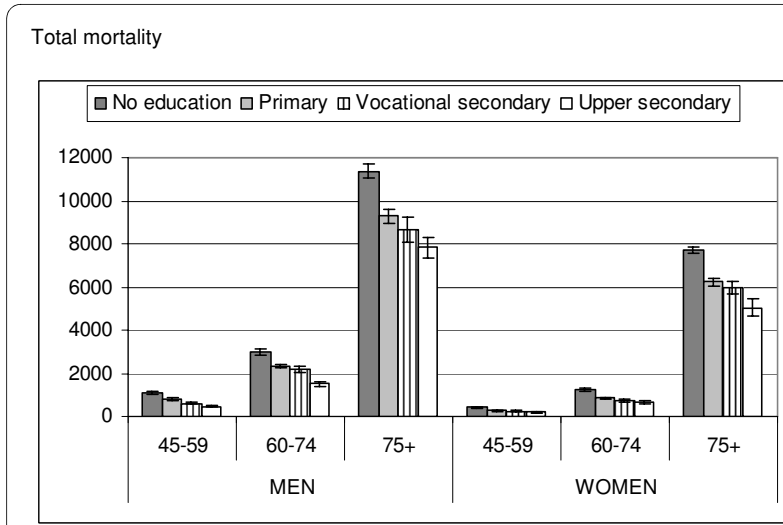

Total cancer mortality

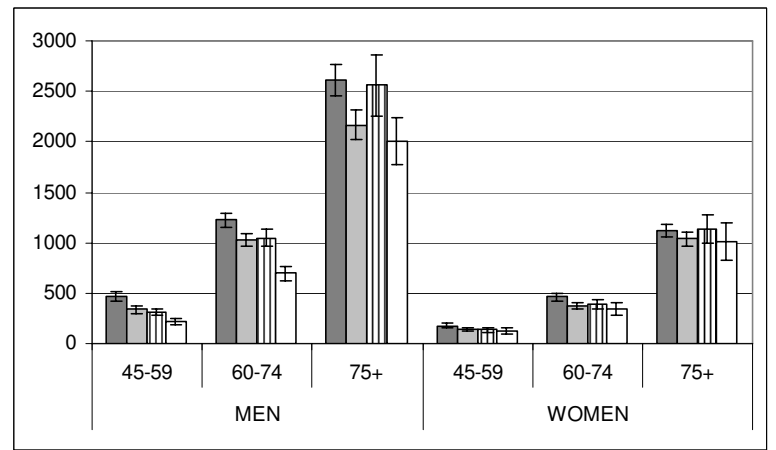

Total cardiovascular mortality

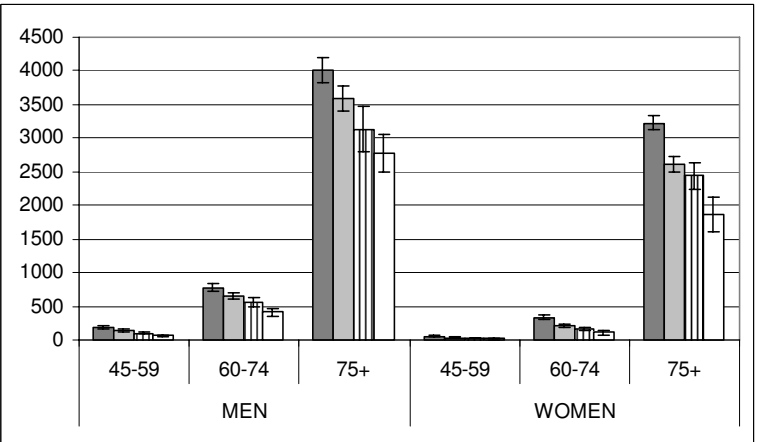

Figure 1 Age-adjusted mortality rate (per 100000 person years) by gender and age group for total and cause specific mortality.

similar to those found for non cancer-non CVD deaths, although based on small numbers of deaths.

Our findings reflect both cohort and age effects. We quantified inequalities using indicators (RII and SII) that were well adapted to compare populations with different educational distribution and thus partly accounted for the cohort effect. Because individuals aged 75 years and more experienced specific life events that younger individuals will not, for instance the First World War, a partly different pattern is likely to be observed in younger cohorts.

\section{Decrease in relative inequalities with age}

Decrease in relative inequalities in mortality with age, for total mortality as well as for cause specific mortality, has already been reported in the literature $[5,7,21]$ and is partly due to a selection effect. Individuals with lower socioeconomic status may die earlier, so that only the healthiest survive into old age, leading to reduced socioeconomic inequalities in mortality. We could then wonder whether socioeconomic inequalities totally disappeared among very old people. A study suggested that, despite a selection effect, socioeconomic inequalities in total mortality in France persist till very old age: inequalities were not any more observed after age 94 [22]. In addition to the selection effect, the decrease in relative inequalities may also partly be explained by the attenuation of the association between risk factors and chronic disease at old age [23].

We observed differences between gender and age groups that may be specific to the French situation. For lung cancer, we found higher mortality rates among higher educated women and among lower educated men, especially among younger men. Among men, we can see the timing of the smoking epidemic with progressively higher smoking rates and consequent higher lung cancer rates among lower educated men. These results reflect the smoking epidemic which is in France at an earlier stage than in Northern European countries [24,25]. For breast cancer, we did not observe any clear association between breast cancer mortality risk and education. Explanations for this finding have already been discussed [26] and include changes in the fertility pattern (mainly age at first birth) and improvement in treatment and screening during the last decades in France. In most countries, higher mortality rates are reported among higher educated women in most European countries $[27,28]$. These inequalities may nevertheless decrease in future years also in other countries as suggested by the weaker association between education and breast cancer mortality reported among younger women in several countries [27].

\section{Increase in absolute inequalities with age}

Increase in absolute inequalities with age has also been reported before [6-8]. The present study documented for the first time inequalities among older people in France, where large inequalities in cancer mortality and an important and increasing contribution of cancer to inequalities in total mortality had been reported, especially among middle aged men [29]. The present study showed that this specific situation does not remain among older people. In this age group, the pattern is more comparable to what is found in Nordic countries and the UK with a large contribution of cardiovascular 
Table 3: Slope index of inequality (SII) and $95 \%$ confidence intervals (CI) for education and mortality rate by age group, gender and causes of death

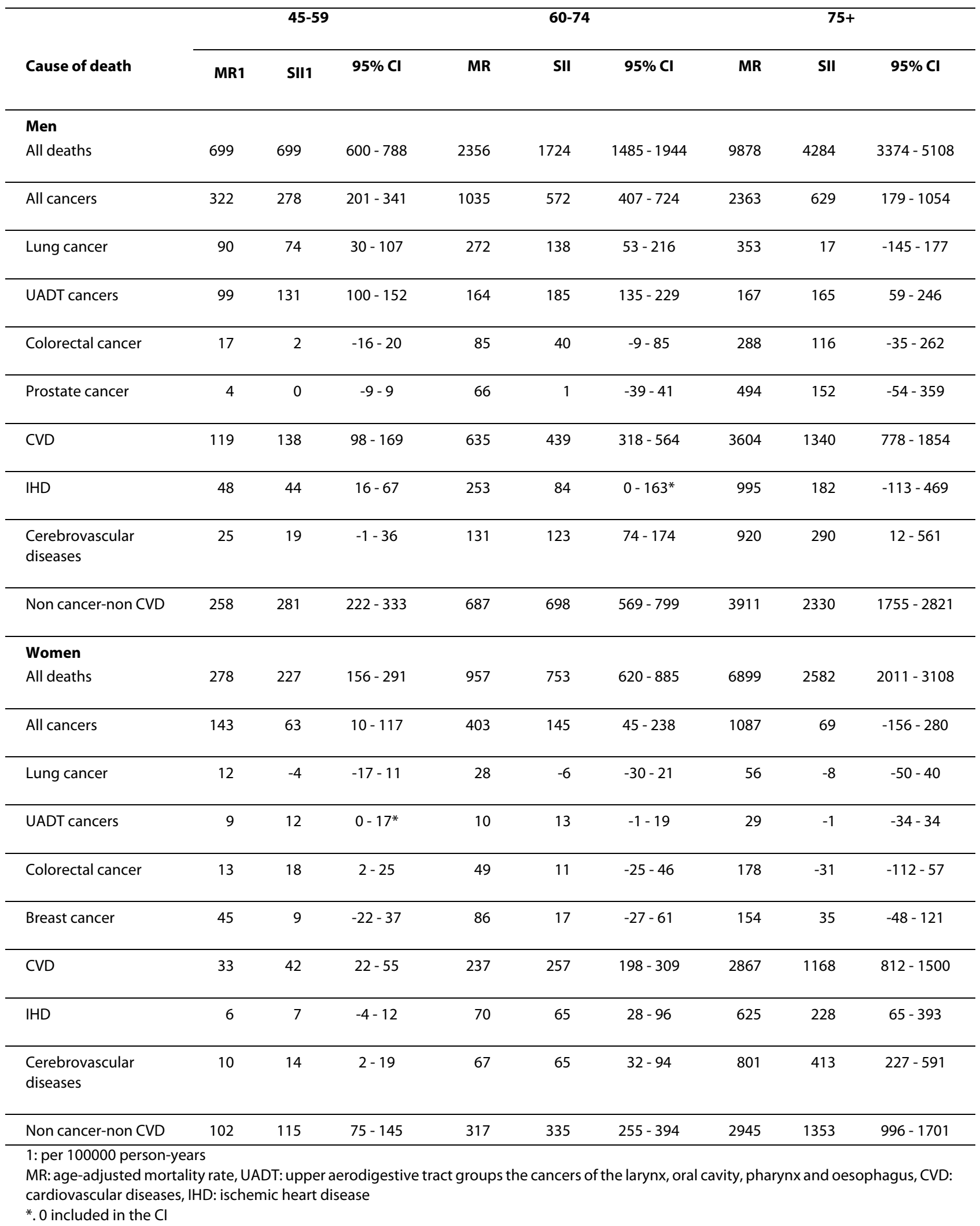


diseases and a decrease in the contribution of cancer $[1,3]$.

Interestingly, whereas absolute inequalities in total mortality increased with age, there was no increase in male absolute inequalities for cancer mortality between the two oldest age groups and we reported a decrease in female absolute inequalities for cancer mortality between these two age groups. This contrasts with the available literature that shows an increase in absolute inequalities for all causes of deaths, including cancer mortality [7]. The explanations for this decrease are not straightforward but several could be suggested. The magnitude of mortality rates may be part of the explanation. Absolute inequalities combine both the level of mortality and the magnitude of relative inequalities. Relative inequalities were only slightly larger for CVD mortality than for cancer mortality among the oldest men. The differences in absolute inequalities are thus mainly driven by variations in mortality rates. In France, cancer mortality rates are especially high among middle aged men but not any more among older people when compared with other European countries. If we cannot rule out the possibility that cancer is more often used as the underlying causes of death in France [30], it is not clear why this would mostly affect younger people. It has been suggested that differences between countries in socioeconomic inequalities in the distribution of risk factors accounted for the differences observed in socioeconomic inequalities between countries. Thus, the pattern of socioeconomic inequalities in France would be partly due to large socioeconomic inequalities in alcohol consumption [31,32] as well as lower rates and modest socioeconomic inequalities for overweight and obesity [33] or smoking [24,25]. This may be especially visible at younger age, when the incidence rate of the chronic disease associated with these risk factors peaked. This may partly explain why mortality rates and socioeconomic inequalities are much higher for cancer than cardiovascular disease among middle aged people. At older age, this specific situation may disappear partly due to selection effect combined with an attenuation of the association between risk factors and chronic diseases at old age.

In a context of ageing population, the share of elderly people among the general population is currently increasing. Because the pattern of socioeconomic inequalities in mortality, and especially the contribution of different causes of death to these inequalities, is likely to differ by age, efficient public health policies aiming at decreasing these inequalities should be defined for each age group. More particularly, the share of cancer deaths to absolute inequalities in total mortality decreased among older French people. In France, reducing socioeconomic inequalities in cancer was recently identified as a main target for public health policies for the next years.
Our results show that, if successfully implemented, public health policies focusing on cancer will substantially reduce inequalities before age 75 in France. They may have comparatively little effect among elderly people. If we want to be successful in decreasing inequalities among older people in France, our results suggest that policies should mostly concentrate on cardiovascular diseases.

\section{Conclusions}

European comparative studies documented a clear North-South divide in socioeconomic inequalities in mortality. They reported a large contribution of cancer deaths to the excess mortality among low educated middle aged men in France and other Latin countries contrary to Northern Europe countries. Our results suggest that this large contribution of cancer deaths is not any more observed among older French men and women. The pattern of socioeconomic inequalities by cause of death among elderly people may thus not largely differ between European countries contrary to what is found at younger age. This should be confirmed with data from other Latin Europe countries.

\section{Competing interests \\ The authors declare that they have no competing interests.}

\section{Authors' contributions}

GM conducted the analysis and wrote the draft. AL, JFC and DL discussed the analyses and the results and commented on the manuscript. All authors approved the final version of the manuscript.

\section{Acknowledgements}

We would like to thank the CepiDC of Inserm and the Demography Department of Insee for their collaboration in the acquisition of the dataset. Gwenn Menvielle was financed by a grant from InCA (Convention n0607-3D1514-06).

\section{Author Details}

IInserm U1018, Epidemiology of occupational and social determinants of health, Center for Research in Epidemiology and Population Health, Inserm, Villejuif, France and 2University of Versailles Saint-Quentin, UMRS 1018, Versailles, France

Received: 30 September 2009 Accepted: 19 May 2010 Published: 19 May 2010

\section{References}

1. Mackenbach JP, Stirbu I, Roskam AJ, Schaap MM, Menvielle G, Leinsalu M, Kunst AE: Socioeconomic inequalities in health in 22 European countries. NEngl J Med 2008, 358(23):2468-2481

2. Mackenbach JP, Kunst AE, Cavelaars AE, Groenhof F, Geurts JJ: Socioeconomic inequalities in morbidity and mortality in western Europe. The EU Working Group on Socioeconomic Inequalities in Health. Lancet 1997, 349(9066):1655-1659.

3. Kunst AE, Groenhof F, Mackenbach JP, Health EW: Occupational class and cause specific mortality in middle aged men in 11 European countries: comparison of population based studies. EU Working Group on Socioeconomic Inequalities in Health. BMJ 1998, 316(7145):1636-1642.

4. Menvielle G, Kunst AE, Stirbu I, Strand BH, Borrell C, Regidor E, Leclerc A, Esnaola S, Bopp M, Lundberg O, Artnik B, Costa G, Deboosere P, Martikainen P, Mackenbach JP: Educational differences in cancer mortality among women and men: a gender pattern that differs across Europe. Br J Cancer 2008, 98(5):1012-1019. 
5. Manor O, Matthews S, Power C: Comparing measures of health inequality. Soc Sci Med 1997, 45(5):761-771.

6. Marmot MG, Shipley MJ: Do socioeconomic differences in mortality persist after retirement? 25 year follow up of civil servants from the first Whitehall study. Bmj 1996, 313(7066):1177-1180.

7. Huisman M, Kunst AE, Bopp M, Borgan JK, Borrell C, Costa G, Deboosere P, Gadeyne S, Glickman M, Marinacci C, Minder C, Regidor E, Valkonen T, Mackenbach JP: Educational inequalities in cause-specific mortality in middle-aged and older men and women in eight western European populations. Lancet 2005, 365(9458):493-500.

8. Rosvall M, Chaix B, Lynch J, Lindstrom M, Merlo J: Contribution of main causes of death to social inequalities in mortality in the whole population of Scania, Sweden. BMC Public Health 2006, 6:79.

9. Rostad B, Schei B, Lund Nilsen TI: Social inequalities in mortality in older women cannot be explained by biological and health behavioural factors - results from a Norwegian health survey (the HUNT Study). Scand J Public Health 2009, 37(4):401-408.

10. Scanlan J: Can we actually measure health disparities? Chance 2006, 19(2):

11. Vagero D, Erikson R: Socioeconomic inequalities in morbidity and mortality in western Europe. Lancet 1997, 350(9076):516. author reply 517-518.

12. Rouault D: The Echantillon Démograhique Permanent: a French equivalent to the Longitudinal Study. Update - News from the LS User Group 1994:5-13.

13. World Health Organisation: International Classification of Diseases. Ninth revision. Geneva 1977.

14. Mackenbach JP, Kunst AE: Measuring the magnitude of socio-economic inequalities in health: an overview of available measures illustrated with two examples from Europe. Soc Sci Med 1997, 44(6):757-771.

15. Pamuk E: Social class inequality in mortality from 1921 to 1972 in England and Wales. Popul Stud 1985, 39:17-31.

16. Efron B, Tibshirani RJ: An introduction to the bootstrap Volume 57. New York: Chapman \& Hall; 1993

17. Galobardes B, Shaw M, Lawlor DA, Lynch JW, Davey Smith G: Indicators of socioeconomic position (part 1). J Epidemiol Community Health 2006 60(1):7-12.

18. Berkman $L F$, Macintyre $S$ : The measurement of social class in health studies:old measures and new formulations. IARC Sci Publ 1997, 138:51-64.

19. Krieger N, Williams DR, Moss NE: Measuring social class in US public health research: concepts, methodologies, and guidelines. Annu Rev Public Health 1997, 18:341-378

20. Ross CE, Mirowsky J: Refining the association between education and health: the effects of quantity, credential, and selectivity. Demography 1999, 36(4):445-460

21. Huisman M, Kunst AE, Andersen O, Bopp M, Borgan JK, Borrell C, Costa G, Deboosere P, Desplanques G, Donkin A, Gadeyne S, Minder C, Regidor E, Spadea T, Valkonen T, Mackenbach JP: Socioeconomic inequalities in mortality among elderly people in 11 European populations. J Epidemiol Community Health 2004, 58(6):468-475.

22. Robert-Bobee I, Cadot O: Mortalité aux grands âges: encore des écarts selon le diplôme et la catégorie sociale. INSEE Première 2007, 1122:.

23. Lewington S, Clarke R, Qizillbash N, Peto R, Collins R: Age-specific relevance of usual blood pressure to vascular mortality: a metaanalysis of individual data for one million adults in 61 prospective studies. Lancet 2002, 360(9349):1903-1913.

24. Huisman M, Kunst AE, Mackenbach JP: Educational inequalities in smoking among men and women aged 16 years and older in 11 European countries. Tob Control 2005, 14(2):106-113.

25. Sasco AJ, Grizeau D, Pobel D, Chatard O, Danzon M: Smoking and social class in France 1974-1991 (en français). Bull Cancer 1994, 81(5):355-359.

26. Menvielle G, Leclerc A, Chastang JF, Luce D, Edisc group: Social inequalities in breast cancer mortality among French women: disappearing educational disparities from 1968 to $1996 . \mathrm{Br} J$ Cancer 2006, 94(1):152-155.

27. Strand BH, Kunst A, Huisman M, Menvielle G, Glickman M, Bopp M, Borell C, Borgan JK, Costa G, Deboosere P, Regidor E, Valkonen T, Mackenbach $J P$ : The reversed social gradient: higher breast cancer mortality in the higher educated compared to lower educated. A comparison of 11 European populations during the 1990s. Eur J Cancer 2007, 43(7):1200-1207.
28. Strand BH, Tverdal A, Claussen B, Zahl PH: Is birth history the key to highly educated women's higher breast cancer mortality? A follow-up study of 500,000 women aged 35-54. Int $J$ Cancer 2005, 117(6):1002-1006.

29. Menvielle G, Chastang JF, Luce D, Leclerc A: [Changing social disparities and mortality in France (1968-1996): cause of death analysis by educational level]. Rev Epidemiol Sante Publique 2007, 55(2):97-105.

30. Percy C, Ries LG, Van Holten VD: The accuracy of liver cancer as the underlying cause of death on death certificates. Public Health Rep 1990, 105(4):361-367.

31. Leclerc A, Lert F, Fabien C: Differential mortality: some comparisons between England and Wales, Finland and France, based on inequality measures. Int J Epidemio/ 1990, 19(4):1001-1010.

32. Menvielle G, Kunst AE, Stirbu I, Borrell C, Bopp M, Regidor E, Heine Strand B, Deboosere P, Lundberg O, Leclerc A, Costa G, Chastang JF, Esnaola S, Martikainen P, Mackenbach JP: Socioeconomic inequalities in alcohol related cancer mortality among men: to what extent do they differ between Western European populations? Int J Cancer 2007, 121(3):649-655

33. Singh-Manoux A, Gourmelen J, Lajnef M, Sabia S, Sitta R, Menvielle G, Melchior M, Nabi H, Lanoe JL, Gueguen A, Lert F: Prevalence of educational inequalities in obesity between 1970 and 2003 in France. Obes Rev 2009, 10(5):511-518.

\section{Pre-publication history}

The pre-publication history for this paper can be accessed here: http://www.biomedcentral.com/1471-2458/10/260/prepub

doi: 10.1186/1471-2458-10-260

Cite this article as: Menvielle et al., Socioeconomic inequalities in cause specific mortality among older people in France BMC Public Health 2010, 10:260

\section{Submit your next manuscript to BioMed Centra and take full advantage of:}

- Convenient online submission

- Thorough peer review

- No space constraints or color figure charges

- Immediate publication on acceptance

- Inclusion in PubMed, CAS, Scopus and Google Scholar

- Research which is freely available for redistribution 